Urszula K. Zawadzka-Pą, PhD, Dominik Kościuk, $P h D$,

Justyna E. Kulikowska-Kulesza, $P h D$,

Ewa Lotko, M.A.,

Faculty of Law, University of Bialystok,

Poland

Anna Brékine, M.A., University of Geneva, Switzerland

\title{
DOES PARTICIPATORY BUDGETING BELONG TO DEMOCRACY OR BUREAUCRACY? CASE STUDY OF BIALYSTOK (POLAND)
}

\section{Introduction}

\section{Background}

$\mathrm{L}$ ocal governance that - in contrast to the previously dominant concept of local government - includes the citizens and the residents of local communities to decision-making process without limitation of their role (as so far the concept of local government) at most to the choosing their representatives in the local elections. Participatory budgeting $(\mathrm{PB})$ is a part of the concept of public governance which assumes the citizens' participation in the decision-making process. This concept constitutes the extension of the concept of New Public Management which began to dominate in the public administration in the eighties of the previous century as the result of the final collapse of belief in the effectiveness of the Weber's model of bureaucratic administration.

Nowadays, the citizens' activity in Poland is mainly limited to the participation in the elections. Using Tocquivile's words ${ }^{1}$ each individual endures being bound, because he sees that it is not a man or a class, but the citizens emerge for a moment from dependency in order to indicate their master, and return to it. There are many men today who accommodate themselves very easily to this type of compromise between administrative despotism and sovereignty of the people, and who think that they deliver that liberty.
They will soon become incapable of properly exercising the great and sole privilege of voting remaining them. In consequence, contemporary societies are struggling with a participation pathology (i.e. the lack of citizens' conviction that participation can help to solve public problems) and with a representation pathology (i.e. the reduced citizens' sense of being represented by those they had elected). This dual pathology can be solved thanks to a participation by invitation appearing when public institution officially opens social dialogue and "admits" the presence of citizens in moments of public debate and decision-making ${ }^{2}$.

All over the world one of the most successfully implemented instrument of participation by invitation is $\mathrm{PB}$, originating from Brazil. It means a year-long decision-making process in which citizens negotiate among themselves and with government officials in organized meetings over the allocation of new capital investment spending on projects ${ }^{3}$. The decisions taken in such a way are incorporated to the local budgets. The introduction of $\mathrm{PB}$ to the traditional local budgetary procedure reduces (but does not eliminate until covering all local government expenditures by $\mathrm{BP})$ the discretional decisions of bureaucrats and officials about the allocation of public expenditures.

Even if there are some BP models, distinguished on the basis different practices observation (Sintomer, Herzberg, Rocke 2014), there is no standardized approach to 
participatory budgeting $(\mathrm{PB})$ as the instrument strengthening the local democracy. Damgaard and Lewis ${ }^{4}$ argue that researches should yield evidence about whether the citizens' participation is over-stretching the concept of accountability, or an essential step to take if the idea of citizen participation is to be taken seriously. Our research constitutes a step in this direction.

\section{Theoretical Framework}

Jensen and Meckling's ${ }^{5}$ principal-agent theory assumes that politicians (agents) chosen (employed) by the citizens (principal) do not always act in the interests of the latter, but seek to realise their own needs. Damgaard and Lewis $^{6}$ basing on the Arnstein's ladder of participation ${ }^{7}$ have distinguished five level of participation in accountability. Climbing the consecutive ladder's steps increases the awareness and control of citizens and enables the creation of the civil society. However, what is needed for citizens to start to climb this ladder is to overcame the learning disabilities universal for every organization as distinguished by P. Senge ${ }^{8}$. Overcoming these learning disabilities should enable creation of civil society and climbing the last ladder's participation, i.e. joint ownership. The latter seems to constitute an important factor enhancing the agent's responsibility and reduce the negative effects of lack of the real ownership relation in public sector, as there are in business between shareholders and managers.

The existence of civil society is crucial to ensure the stabilization of the democracy and to limit the authoritarian aspirations. Murray ${ }^{9}$ has noticed that the condition of formation of the tendril of the community and in consequence of the civil society is the real possibility and the need of filling functions by this community. The execution of some tasks or services by public institutions is the factor limiting citizens' involvement. For instance, existence of social assistance reduce the citizens' sense of responsibility of helping people in need. Similarly, if the decisions at the local and central level are taken by politicians, the citizens do not see the need of participation in decision-making process. In consequence, the functions' centralization cause the atomization of modern, urban societies. However it does not means that this centralization is indispensably linked with the modernization process, it is rather results from the political choice ${ }^{10}$. The lack of tendrils' community weaken the civil society, essential guarantee for democracy. Thus, we would like that the citizens' active participation in PB was an significant "function" to fulfil, and in consequence an important instrument for shaping the civil society.

\section{Methodology}

The paper presents the grounds for the wider project "Participatory budgeting - success or crisis of local democracy? Comparative legal study" aiming to explore what factors (dependent and independent from the policy makers) make from BP the instrument strengthening the local democracy and what are the barriers to fully exploit its potential. In other words, the research attempts to answer the question whether PB - in the current legal frameworks and practices - claims to be the institution strengthening the democratization processes or whether it is merely a tool that serves only to create the appearance of participation of wide social groups in the exercise of public bureaucracy.

The scientific area of this paper is the implementation and functioning of the in the city of Bialystok (Poland). This case study is representative example of Polish city being the representative for Poland PB case study. Poland's local government structure in Poland is compositing of three levels: communes (some communes has also the status of a city), departments and regions. There is 16 cities being the regions' capitals, Bialystok in terms of population is on the $11^{\text {th }}$ rank. PB in Poland is relatively new instrument. The first PB was implemented in Poland in 2012 (Sopot), whereas in Bialystok in 2014. Every year the Bialystok local authorities introduce the changes in $\mathrm{PB}$ procedure, thus it seem that they try to find the optimal solutions. The amount allocated to PB in Poland are comparable in all local government units and in general do not exceed $1 \%$ of local budget. For instance, cities being the regions' capitals (16 in total) in 2016 allocated between $0,17 \%$ (Warsaw) and 0,96\% (Wroclaw, Lodz, Zielona Gora). In Bialystok it was allocated $0,89 \%$ of local budget.

The scientific problem is be the answer to the following question: does $\mathrm{PB}$ can be the instrument of strengthening of the local democracy, or rather it only testifies about the crisis of existing democratic mechanisms. According to the scientific hypothesis, PB can both strengthen democracy (by enhancing citizens' participation, increasing citizen's care about life of the inhabitants of the local community (citizens' accountability) and by the improvement of the allocation of local resources), or on the contrary, may not bring any positive results. Thus the scientific goal of the paper is to examine the factors (dependent and independent on the decision-makers' actions) determining the success of $\mathrm{PB}$, and therefore determination what influences on the strengthening of local democracy thanks to $\mathrm{PB}$ and what are the barriers to take advantages of its potential. To this 
aim, we propose the theoretical model of the PB strengthening the local democracy.

\section{Learning as the Core of the Optimal Model of PB Strengthening the Democracy}

Damgaard and Lewis ${ }^{11}$ basing on the Arnstein's ladder of participation ${ }^{12}$ have distinguished five level of participation in accountability. Climbing the consecutive ladder's steps increases the awareness and control of citizens and enables the creation of the civil society. However, what is needed for citizens to start to climb this ladder is to overcame the learning disabilities universal for every organization as distinguished by P. Senge ${ }^{13}$. Overcoming these learning disabilities should enable climbing the last ladder's participation, i.e. joint ownership. The latter seems to constitute an important factor enhancing the agent's responsibility and reduce the negative effects of lack of the real ownership relation in public sector, as there are in business between shareholders and managers. Consequently, the developed civil society (principal) is capable to motivate politicians (agents) and to make them accountable. The cooperation of the accountable politicians with the employees of public administration, capable to overcome at least partially, their learning disabilities ${ }^{14}$ seems necessary to effectively implement the PB.

The $\mathrm{PB}$ to strengthen the democracy requires active involvement of three groups of the actors, i.e. citizen (the city's residents), their representatives (the local councillors) and the bureaucrats (the city's president and city hall's employees). The core of the model is the continuous and mutual learning of all three groups. Councillors and public officials learn social needs through information meetings, promotion campaigns and substantive assistance in prepare project proposals. Citizens learn the PB procedures and principles, the local investments realization, they get to know about the public expenditures costs.

The learning process should enhance the representatives', bureaucrats and citizen' accountability moral values, the citizens' representation and participation and the transparency of public spending. The details of the model are presented on the following graph.
Graph 1. The Optimal Model of Participatory Budgeting Strengthening the Democracy

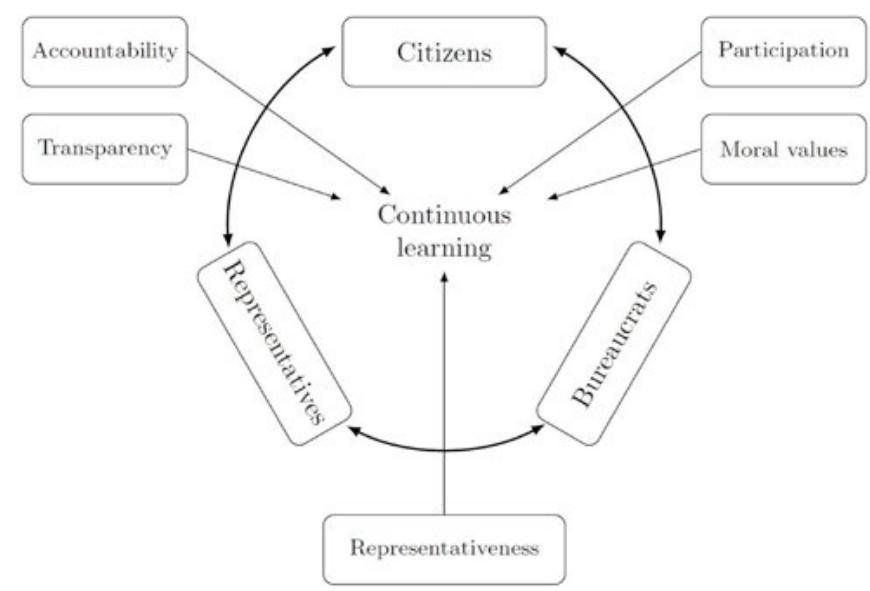

In Bialystok city each PB edition has been in some extend different and, as the councillors suggested, it is crucial to learn from the past ones. After each edition people responsible for the $\mathrm{PB}$ procedure should reach out and talk to citizens, councillors and officials in order to gain sufficient knowledge about what went wrong, what we can improve, what should we look out for - a proper evaluation should be conducted and appropriate conclusions should be drawn and implemented. Additionally, the councillors of the opposition party wants that the authorities make every effort to gradually teach local society of participation - to show the citizens that their opinion matters. To achieve that the representative of the opposition suggests that the local authorities - creating BP procedure - should focus on one big, city-wide project and a lot of micro-projects (e.g. building a lamp, repairing a pavement or building a new one etc.) with a visible, displayed information about the nature of the financing. That way people every day will see the "effect" and step by step they will see that their involvement made a change in their environment. And maybe that way they will understand that the more they get involved, the more they can affect the way the public found are being spend and take the responsibility.

\section{Determinants of the Optimal Model of PB - Case Study of Bialystok (Poland)}

\section{Accountability}

The accountability, the first determinant of our model, can be seen from the point of view of three actors, whereby the behaviour of citizens directly influences the behaviour of others. While it is assumed that the councillors and 
politicians bear the responsibility for local issues (as included in their task obligations), the results of the present research disclose that citizens, who acquire a sense of accountability for local issues by participating in BP, complement these two aforementioned groups. Indeed, the very process of promoting and informing about $\mathrm{BP}$ triggers the acquirement of social awareness and responsibility of local communities for public (local) affairs.

Our research has shown that up to $45 \%$ of the surveyed residents of Bialystok believe that they have no impact on the implementation of public affairs. Surprisingly, the more a public matter is close to a person's place of residence, the lesser the perceived impact in its realization and the lesser the interest in its realization. Consequently, it is difficult to require that the public felt responsible for public affairs. However, there is a contradiction at this stage, because on the one hand we are dealing with a low feeling of necessity to be actively involved in local issues, and on the other hand, the respondents predominantly stated that $\mathrm{BP}$ allows for the realization of projects that serve them both personally and collectively, and that the municipality will develop in the areas most needed for the local community. Respondents also came to the conclusion that $\mathrm{BP}$ will increase their responsibility for local issues, and that the administrative organs and offices will gain knowledge about the needs of their citizens. Nonetheless, given the citizens' belief about their negligible impact in the implementation of public affairs, one may argue that if BP really granted the citizens an actual impact in local issues, then their impact on these matters should be greater than their influence on the affairs of the state as a whole (through selecting representatives to the central authorities). Consequently, it is difficult to recognize that $\mathrm{BP}$ increases the citizens' accountability for public affairs. The representatives of both the ruling party and the opposition one of Bialystok have confirmed the residents' convictions by clearly stressing that the public officials (the mayor and the councillors) bears the accountability for the implementation and development of BP. However, the condition for the existence of civil society is on the one hand the responsibility of the citizens and, on the other hand, the responsibility towards the citizens (principal-agent), which is why the municipal authorities (the politicians) play such an important role by obtaining from the principal, i.e., the citizens, the legitimacy to rule and take political decisions, including decisions about the amount allocated to BP. Nonetheless, for the principal to effectively influence the political decisions, there should a civil society. Therefore, citizens fittingly want that the $\mathrm{PB}$ evaluation could be carried out immediately after the completion of the process associated with the implementation of particular projects, or even during the edition, rather than after the completion and settlement of a complete PB edition (in practice, it is usually 2 years). Only then, would there be a response to the difficulties and problems, and the citizens would obtain information about the processes that affect them. Furthermore, the learning of democracy has a chance to bring the most optimal effect, i.e. protection against committing the same mistakes in the next editions.

What is more, as shown by surveys, citizens have no explicit opinion as to whether their interests - in terms of its investments local - are best represented by politicians, administration, or are in a position to ensure their implementation. However, it is interesting to note that the respondents believe that the officials have virtually no influence on the implementation of local investments ${ }^{15}$ (i.e. people who actually carry out the greater part of the activities leading to the implementation of local investment (organization of tenders, construction, contracting, etc.). In addition, there is a noticeable lack of responsibility of officials for the work, substantive unpreparedness and poor involvement, and all of this makes the sphere of public administration less respected and trusted.

\section{Participation}

What is needed to know about the citizens' participation in Poland it is its context. In general Polish citizens, apart the national and local elections (where the turnout does not exceed 50\%) do not have many chances to civil activities. In the contemporary history of Poland, from 1989, there were only four national referendums. Also at the local level, the referendum is not popular as well, e.g. in Bialystok city it was organized only once.

Concerning participation in $\mathrm{PB}$, the number of participants gradually increases. Partially it results from the enhance of citizens' involvement and knowledge, partially from enlargement of the scope of people eligible to vote (currently, even children living in Bialystok and having the parent' consent can take part in). In 2014, the turnout was $14 \%$ of Bialystok residents, in $2015-16.6 \%$, in $2016-17 \%$. However still the low participation constitutes an important $\mathrm{PB}$ problem. One of the main reasons are low, if not symbolic, funds allocated to PB (less than $1 \%$ of local budget). Some citizens would like to enhance the funds level up to $80 \%$. Some citizens think that they have chosen their representatives that should take more about city' spending. Another say that and so the citizens will not have the influence on public affairs. 
On the other hand, there are some changes that positively influence the citizens' participation, i.e. diversified forms of $\mathrm{PB}$ promotion, several possible ways of voting (traditional, online), the public officials' assistance in project proposal' preparation. The Bialystok counsellors believe that one of the possible solutions is to show to citizens a physical participations' result near them, so they can walk every day near that result, see the result and they can realize that if they participate in the BP procedure they can influence on their neighbourhood. After they "learn" to participate in their closest surroundings, maybe they would more consciously take part in civic activities.

\section{Representativeness}

In the democratic countries, the citizens chose their representatives in elections to local and central decision-making bodies to represent their interests hoping to provide the electoral representation that however may provide insufficient. This criticism provided the grounds for the representative bureaucracy theor ${ }^{16}$ based on the premise that a diverse bureaucracy will lead to more responsive public policy in the face of lack electoral accountability. The passive representation exists when a bureaucracy's demographic characteristics reflect or mirror the demographic characteristics of the general population. If the passive representation leads to policy outcomes that reflect the interests of all groups represented, it is transformed to the active representation ${ }^{17}$. We consider that this division remains valid also for the participatory representation. The passive participatory representation exists when the PB participants' demographic characteristics reflect or mirror the demographic characteristics of the general population, whereas the active participatory representation leads to policy outcomes that reflect the interests of all groups represented.

The citizens agree that the active participatory representation of excluded groups (e.g. religious, ethnicity, gender, disability, age) is important, however they do not see the solutions promoting it. Some minorities (e.g. the elderly or disable people) having limited access to the information are ignored in $\mathrm{PB}$ procedure. It is difficult to vote the project that is needed only for the small number of people, because the project gathering the more votes wins. Another parking or playground useful for more residents has much more chanced to be voted that the facilities for the disabled people. However sometimes the playgrounds or sport facilities do not fulfil the elderly needs. Even if in citizens' opinion, the minorities' representativeness seems important, both surveyed councillors doubt ensuring it would be desirable and feasible. I think this is not a good idea. There are too many categories of such kind of groups - separate budget for women and men, separate budget for dog owners and cat owners ?! In my opinion there is no possibility of selecting all the groups of interests which would have to be ensured. I think it is important and it is needed to implement those $B P$ projects that are accepted by the majority of the citizens.

The only exception where the active participatory representation can be ensured and what is more accepted concern the territorial minorities e.g. residents of particular city's districts. In Bialystok, this can be achieved thanks to the distinction between the projects general for whole city (250 000 PLN - 1000000 PLN) and the projects fulfilling only the needs of a particular district (less than 250000 PLN). In Bialystok in 2016, 18 general projects and 21 district' projects are realized. For 2017 to ensure the more equal territorial representativeness $70 \%$ of $\mathrm{PB}$ resources will be equally distributed for each of 28 districts, resting $30 \%$ of PB will be designed for general city interest projects. Ensuring the participatory representation (the active and passive one) requires citizens' engagement, whereas the Bialystok's citizens in general do not except the need of taking decisions by themselves. The activity of the majority of them is limited to taking part in local elections. Only $20 \%$ of surveyed declared their engagement in PB procedures, referendums and consultation. However such turnout does not enable achievement nor passive neither active participatory representation.

\section{Transparency}

One of the most important factors enhancing the process of the strengthening democracy PB learning is the transparency of $\mathrm{PB}$ principles and procedures. It depends on the officials' and the politicians' decisions, subsequently influencing the citizens' participation. The analysis of evolution of the $\mathrm{BP}$ procedures in Bialystok enables to say that some positive changes were made. The transparency of the process results mainly from the detailed $\mathrm{PB}$ evaluation process. The preparation of the evaluation document was preceded by the open meeting with the Bialystok Mayor, the councillors, members of the PB city's team, authors of $\mathrm{PB}$ projects and other citizens. As a result of these discussions the new, much more transparent website devoted inclusively to PB (schedule, formularies, procedures) was created. Positively should also be considered the available information about the status of ongoing and finished projects posted on the interactive map enabling to easily find all needed information about the project. 
Even if the PB changes should be appreciated positively, there are some important gaps of the whole process. First, it concern the lack of appeals against the committee's decision rejecting BP projects or the lack of explicit procedure criteria (approval of projects, evaluation). Second, under the current state of law, the local authorities are not obliged to follow the will of the citizens expressed in BP. It is not based on current standards and regulations but on a kind of social contract with the local community, declaring that the authority will actually put into force the results of the consultation (implement the selected projects by the locals). Third, the municipal authorities in our legal system are not able to bring an investment from BP found to an end fast enough and it raises questions in the society what usually end with the impression that citizens have been deceived. Fourth, the lack of transparency can be connected to the types of permissible projects. The soft project, financing or particular services (i.e. the flying trainings) for small group of beneficiaries can lead to the anomalies and some people can use them to extort money.

Moreover, there is an unresolved problem of low amount of the expenditure allocated for $\mathrm{PB}$. The higher amount is designated to $\mathrm{PB}$, the higher not only local spending participation (as mentioned above) but also the higher transparency. In consequence, the citizens possess the transparent information about the small part of local spending. The transparency of the local budget as a whole could be ensured via the performance budgeting based on the results indicators. However, the local government units in Poland are not willing to prepare, use for managerial purposes and especially make them available online, that would effectively enhance the transparency of the local spending.

\section{Moral values}

Moral values, such as justice, honesty, action in the public interest determine the attitudes and expectations of the citizens towards politicians, who should make optimal decisions ${ }^{18}$. In Poland, society does not trust neither the politicians, nor the bureaucrats, accusing the first for lack of truthfulness, the second for lack of competence. What is interesting, a ruling party representative asked about the moral values that should be the PB foundations, enumerated transparency (mentioned in subsection 3.4.) and fairness, however quickly he added that the question of moral values has really secondary importance because the priority is to increase the activity and the commitment of the local authorities, councillors and the citizens in the BP process. However apparently he has not noticed that the citizens' participation can be enhanced by shaping their attitudes and moral values. The second interlocutor that was asked the same question pointed on the transparency, but also on the need to prepare the ethical code applicable to all $\mathrm{PB}$ actors.

The $\mathrm{PB}$ procedure in Poland do not result from any central legislation, but from the local regulations, whereas the citizens' not trusting in the good will of the local politicians prefer that that $\mathrm{PB}$ principles were regulated by the central parliament act. As the consequence of lack of national legal provisions, the amount of resources allocated to $\mathrm{PB}$ is flexible. That is why, the $\mathrm{PB}$ promotion by the local politicians is often seen negatively, as the element of their electoral campaign. Moreover, it happens that the bureaucrats asked by citizens to decide about some public expenditure (e.g. the renovation of pavement) refuse, saying that this expenditure can be financed from $\mathrm{PB}$. However the $\mathrm{PB}$ funds are very limited and require gathering the majority of votes. On the other hand, let's note that $\mathrm{PB}$ can positively influence on the citizens' moral values because some of them start to think and act for the collective interest.

\section{Implications and conclusions}

The paper presents the theoretical, optimal model of PB strengthening the democracy basing on the mutual citizens', bureaucrats' and representatives' learning of accountability, participation, transparency, representativeness and moral values. The existence of this model was tested on the case study of the Polish city (Bialystok). Our researches has confirmed that the citizens strongly believe in the idea of PB and would like to change their surroundings with this instrument of local governance. They see the chances to enhance citizens' accountability and participation. However the right to the transparent information, citizens' accountability, participation and representativeness are extremely limited due to the critically low expenditure percentage allowed for $\mathrm{PB}$. Moreover, this positive thinking is enhanced by the politicians and officials who give these chances to participate and to take the decisions. They create the favourable conditions for PB development, such as transparent information about all elements of $\mathrm{PB}$, differentiated forms of voting, an extensive information campaign and the vast scope of people entitled to vote, official consultations with citizens.

In consequence, the main problem concerns the politicians' and officials' attitudes and moral values, particularly the creation of the illusion of providing for citizens the 
opportunities of participation and accountability, and in consequence enhancing the democracy, whereas the latter often are symbolic. PB imply the openness and the type of procedure that has been already almost unknown for relations between public administration and citizens in Poland, the country still with the traces of the post-communist reality. The creation of such illusion in some cases can result from more or less conscious manipulation of the representatives and/or the bureaucrats.

In consequence, referring to the research hypothesis the $\mathrm{PB}$ in the Bialystok case study, PB do not imply the success of the democracy, but rather only its failure that resulted in seeking the instruments aiming to enhance this democracy. What even worse, such illusion of citizens' participation and accountability can be even dangerous for the democracy. Under the cover of $\mathrm{PB}$, using the illusion of the citizens' participation, it is easier to hide the allocation of the rest of public spending from the unconscious citizens' control. The further studies should concentrate on this danger, especially in the context other foreign experiences. ${ }^{19}$

\section{$\underline{\text { Abstract }}$}

The paper presents the grounds for the wider project "Participatory budgeting - success or crisis of local democracy? Comparative legal study, aiming to explore what factors (dependent and independent from the policy makers) make from BP the instrument strengthening the local democracy and what are the barriers to fully exploit its potential. To this aim, we propose the theoretical model of the PB strengthening the local democracy. To test its validity, using the case of one of the Polish cities (Bialystok), we use the mix research method: the desk research, the qualitative and quantitative surveys and the qualitative interviews. The preliminary results have shown that $\mathrm{PB}$ do not imply the success of the democracy, but rather only its failure and the illusion of the citizens' participation.

\section{BIBLIOGRAPHY}

1. Allegretti G., Paying Attention To The Participants' Perceptions in Order to Trigger A Virtuous Circle, in: Hope For Democracy - 25 Years of Participatory Bugeting, Nelson Dias (org) 2014.

2. Arnstein, S., A Ladder of Citizen Participation, "Journal of the American Planning Association" 1969, vol. 35.

3. Damgaard B., Lewis J.M., Accountability and Citizen Participation, in: M. Bovens (ed.), Oxford Handbook of Public Accountability, Oxford 2014.

4. De Tocqueville A., Democracy in America, Liberty Fund 2010.
5. Huberts L., The Integrity of Governance, What it is, What We Know, What is Done, and Where to Go, Palgrave Macmillan 2014.

6. Jensen M.C., Meckling W.H., Theory of the Firm: Managerial Behavior, Agency Costs and Ownership Structure, "Journal of Financial Economics" 1976, no. 4.

7. Kennedy B., Unraveling Representative Bureaucracy: A Systematic. Analysis of the Literature, "Administration \& Society" 2014, vol. 46 (4).

8. Kingsly D.J., Representative Bureaucracy: An Interpretation of the British Civil Service, Yellow Springs, OH: Antioch Press 1944.

9. Krislov S., Representative Bureaucracy, Ouid Pro Books, New Orleans, Louisiana 1974.

10. Mosher F.C., Democracy and the Public Service, Oxford University Press, New York 1968.

11. Murray C., The Tendrils of Community, in: D. Boaz (ed.), The Libertarian Reader, New York 1998.

12. Senge P., The Fifth Discipline. The Art \& Practice of the Learning Organization, Currency Doubleday, New York 1990.

13. Wampler B., When Does Participatory Democracy Deepen the Quality of Democracy, "Comparative Politcs" 2008, no. $41(1)$.

A. de Tocqueville, Democracy in America, Liberty Fund 2010

G. Allegretti, Paying Attention To The Participants' Perceptions in Order to Trigger A Virtuous Circle, in: Hope For Democracy - 25 Years of Participatory Bugeting, Nelson Dias (org) 2014.

3 B. Wampler, When Does Participatory Democracy Deepen the Quality of Democracy, "Comparative Politcs" 2008, no. 41 (1).

4 B. Damgaard, J.M. Lewis, Accountability and Citizen Participation, in: M. Bovens (ed.), Oxford Handbook of Public Accountability, Oxford 2014.

5 M.C. Jensen, W.H. Meckling, Theory of the Firm: Managerial Behavior, Agency Costs and Ownership Structure, "Journal of Financial Economics" 1976, no. 4.

6 B. Damgaard, J.M. Lewis, op. cit.

S. Arnstein, A Ladder of Citizen Participation, "Journal of the American Planning Association" 1969, vol. 35.

${ }^{8}$ P. Senge, The Fifth Discipline. The Art \& Practice of the Learning Organization, Currency Doubleday, New York 1990.

9 C. Murray, The Tendrils of Community, in: D. Boaz (ed.), The Libertarian Reader, New York 1998.

${ }_{10}$ Ibidem.

${ }^{11}$ B. Damgaard, J.M. Lewis, op. cit.

${ }^{12}$ S. Arnstein, op. cit.

${ }_{13}$ P. Senge, op. cit.

${ }_{14}$ Ibidem.

${ }^{15}$ Only 5\% of respondents said that the administration (officials) represents their interests in the implementation of local investments.

${ }^{16}$ D.J. Kingsly, Representative Bureaucracy: An Interpretation of the British Civil Service, Yellow Springs, OH: Antioch Press 1944.

${ }_{17}$ F.C. Mosher, Democracy and the Public Service, New York: Oxford University Press 1968.

${ }^{18}$ L. Huberts, The Integrity of Governance, What it is, What We Know, What is Done, and Where to Go, Palgrave Macmillan 2014.

19 The paper prepared under the project of the Polish National Centre for Science, no. 2014/15/D/HS5/02684. 